\title{
Article \\ Simulation and Economic Research of Circulating Cooling Water Waste Heat and Water Resource Recovery System
}

\author{
Li Yang ${ }^{1,2}{ }^{\oplus}$, Yunfeng Ren ${ }^{3}$, Zhihua Wang ${ }^{4}{ }^{-}$, Zhouming Hang ${ }^{5, *}$ and Yunxia Luo ${ }^{1,2}$ \\ 1 Key Laboratory for Technology in Rural Water Management of Zhejiang Province, Zhejiang University of \\ Water Resources and Electric Power, Hangzhou 310018, China; yangl@zjweu.edu.cn (L.Y.); \\ luoyx@zjweu.edu.cn (Y.L.) \\ 2 The College of Electrical Engineering, Zhejiang University of Water Resources and Electric Power, \\ Hangzhou 310018, China \\ 3 Zhejiang Pyneo Technology Limited Company, Hangzhou 311121, China; renyunfeng@mecc.sinosteel.com \\ 4 State Key Laboratory of Clean Energy Utilization, Zhejiang University, Hangzhou 310012, China; \\ wangzh@zju.edu.cn \\ 5 College of Mechanical and Automotive Engineering, Zhejiang University of Water Resources and Electric \\ Power, Hangzhou 310018, China \\ * Correspondence: hangzhm@zjweu.edu.cn
}

check for updates

Citation: Yang, L.; Ren, Y.; Wang, Z.; Hang, Z.; Luo, Y. Simulation and Economic Research of Circulating Cooling Water Waste Heat and Water Resource Recovery System. Energies 2021, 14, 2496. https://doi.org/ $10.3390 /$ en14092496

Academic Editor: Andrea Frazzica

Received: 29 March 2021

Accepted: 22 April 2021

Published: 27 April 2021

Publisher's Note: MDPI stays neutral with regard to jurisdictional claims in published maps and institutional affiliations.

Copyright: (c) 2021 by the authors Licensee MDPI, Basel, Switzerland. This article is an open access article distributed under the terms and conditions of the Creative Commons Attribution (CC BY) license (https:// creativecommons.org/licenses/by/ $4.0 /)$.

\begin{abstract}
Industrial circulating cooling water contains a large amount of low-quality energy, which is lost to the environment through cooling towers. It is of great significance and potential to recover the waste heat to improve energy-saving effects and economic efficiency. However, the effect of common water harvesting and energy saving devices is not significant. Heat pumps have been shown to be effective in improving low-quality heat energy in energy conversion systems, although there are not many applications of heat pump scenarios in engineering practice. Based on this, a recovery solution of circulating cooling water waste heat and water resource using lithium bromide absorption heat pump has been put forward. The energy-saving performance of the recovery system was simulated and analyzed using Aspen Plus V10.0 (Bedford, MA, USA) to explore the effects of the parameters of the working medium in evaporators, condensers, absorbers, generators, heat exchangers, etc., and the modelling results indicated that the evaporation pressure and temperature have a great influence on the system COP (coefficient of performance) and can raise the thermal economy of the system. The heat from driving steam and heating capacity both increased with the increase in generating temperature, while the increase in temperature difference between evaporation and condensation inhibits the COP of heat pump systems. Furthermore, economic analyses and comparisons of the recovery solutions were conducted and the recovery solution of circulating cooling water waste heat with heat pump had the best economic performance due to the annual income from the recovery of waste heat and water resource. The static payback period results indicate that the recovery solution from circulating cooling water waste heat with a heat pump has better economic performance than the scenario with a cooling tower. The waste heat recovery solution with a heat pump can improve the thermal economy of the system and has a great guiding significance for engineering practice.
\end{abstract}

Keywords: heat pump; Aspen Plus; waste heat; COP; economic analysis

\section{Introduction}

As the global energy crisis intensifies day by day, the greenhouse effect and the ecological environment problem become more and more prominent; therefore, developing clean, renewable energy and improving energy efficiency are the most important ways of sustainable development with energy conservation and emission reductions. It is projected that this will reduce about $40 \%$ of global power in 2040 (19\% of transportation energy demand and $25 \%$ of heat demand) [1]. Approximately $72 \%$ of the global primary energy consumption is lost during energy conversion [2]; therefore, it is of great significance 
and potential to make full use of the waste heat [3]. A lot of effort has been focused on saving and recovering energy. Sheikholeslami [4] studied thermal units for the heat recovery of exhaust gas of engines using simulations and experiments. Wang [5] presented a process for recovering waste heat and water from high-humidity flue gas after using a wet flue gas desulfurization scrubber. Some cutting-edge research [6,7] has used advanced nano-fluid technology to study the thermal performance of heat exchangers to improve energy efficiency.

In all available waste heat resources, waste heat carried by industrial circulating cooling water has been proven to be the largest and the highest proportion. The evaporated water loss from cooling towers accounts for more than $50 \%$ of the total water consumption of the whole system [8]. Considering the shortage of water resources, the increase in sewage discharge and the increasingly strict control policies of wastewater discharge, studies on energy-saving and water-saving technology of waste heat and water resource recovery of industrial circulating cooling water has become an urgent task. Effective measures must be taken to recover waste heat from industrial circulating cooling water, which can improve the efficiency of energy and energy utilization. A great deal of research has been conducted. Notaro [9] and Freni [10] presented a decision support tool and efficient measures to test the water and energy balance of an integrated system. Zhu [11] established a comprehensive evaluation index system for circulating cooling water systems through the in-depth analysis of the operating mechanism, which fulfilled a complete energy-saving evaluation of the system in various aspects. Ma [12] put forward the feasible direction of optimizing the design of several cooling towers to find new energy saving technologies with the circulating water. Cai [13] developed a virtual simulation scene of the circulating water system to study the pump frequency conversion and energy saving in the circulating water system. Terzi [14] dealt with the design and implementation of a model predictive control algorithm for an industrial recirculating cooling water system and verified the potentialities of the proposed solution in terms of energy savings.

However, it is very difficult to make full use of circulating cooling water due to the low temperature and low quality. The upgrading and utilization of low-quality heat is an important technique to recover the waste heat of industrial circulating cooling water. Research shows that heat pump technology can enhance the utilization of low-grade thermal energy [15] and upgrade the low-grade heat to make recycling easier. Heat pump technology has played an important role in energy supply systems over the past decade; there have been many studies on the energy-saving technology of heat pumps to recover waste heat and improve energy efficiency, and some progress has been made from experimental and theoretical research to pilot-scale process. Li [16] recovered waste heat from thermal power to heat the primary network water supply using several absorption heat pumps and analyzed the economic benefits. Gou [17] integrated air source heat pumps and wastewater source heat pumps and incorporated a preheater to recover shower wastewater heat, improving the total COP of the system up to 6.588. Wang [18] introduced an exergoeconomic criterion to measure the exergy performance of each type of heat pump and assist the screening of industrial heat pumps, considering the economic impact. Zhang [19] offered an effective way to recover waste heat in urban wastewater using wastewater source heat pumps; the COP of this system was 9.52\% higher. Estefanía [20] studied an energy recovery system from a low-grade temperature source based on heat pumps for domestic hot water. Liu [21] revealed the working domains of a hybrid absorption-compression heat pump for high-temperature $(>403 \mathrm{~K})$ saturated steam production and obtained its optimized thermodynamic performance at different conditions.

Lithium bromide-water working pairs have excellent physical properties for absorption heat pumps; lithium bromide absorption heat pumps have been widely used in industrial waste heat recovery. However, the applications of lithium bromide absorption heat pumps in industrial recirculating cooling water systems and related research are rare, because the amount of industrial circulating water is very large and the heat loss through cooling tower is huge; at present, the conventional energy-saving measure is to 
install water-collecting devices, although the effect is not significant, or to collect waste heat to heat the network water supply. How to efficiently recover and use the waste heat of circulating cooling water was the purpose of the present study. This study established a circulating cooling water waste heat and water resource recovery system with lithium bromide absorption heat pump technology and assessed the energy-saving performance of the system using a reliable numerical methodology based on Aspen Plus simulation. The influence of several operation parameters on the system COP is discussed, including economic analysis. The result can provide the theoretical basis and reference for the practical applications of low-grade waste heat using heat pump technology.

\section{Materials and Methods}

Aspen Plus is general process simulation software with common theoretical bases on the fundamental equation of states, transfer equations, and can be used in the chemical industry and fields of heat pumps and refrigeration [22]. In the present study, Aspen Plus V10.0 was used to model the whole process simulation of the system, and to design and optimize the operating parameters, which is the basis of the system for industrial application.

\subsection{Introduction of System}

The total circulating cooling water flow rate is $80,000 \mathrm{t} / \mathrm{h}$ in a thermal power plant, and 16 new cooling towers with a circulating water treatment capacity of $5000 \mathrm{t} / \mathrm{h}$ per unit were planned. The outlet circulating water $(316 \mathrm{~K})$ of the power plant flows directly into the cooling tower, cools down to $305 \mathrm{~K}$, and then the inlet circulating water from the cooling tower returns to the cooling water main pipe, as in most power plants.

This design scenario established a recovery system of circulating cooling wastewater heat and water resource to recover circulating cooling water to raise the heat efficiency of the system with lithium bromide absorption heat pump technology, which is an important form for low-grade heat energy applications [23]. A certain percentage of circulating cooling water from the $316 \mathrm{~K}, 5000 \mathrm{t} / \mathrm{h}$ main pipe is extracted to enter into the heat pump for precooling, and the precooled circulating water is returned to the main pipe, mingles with the original $316 \mathrm{~K}$ circulating water, and then enters the cooling tower together. After cooling in the cooling tower and assuming that the evaporation water loss was $1.71 \%$, the $305 \mathrm{~K}, 4914.5 \mathrm{t} / \mathrm{h}$ circulating water returned to the internal users in the thermal plant. The cycle model of design scenario in Aspen Plus is shown in Figure 1, and the main symbols used in the models are described in Table 1.

Temperature and the humidity content of wet saturated air at the cooling tower exit decreased due to the precooling of circulating water. Moreover, the decrease in temperature and the humidity content of wet saturated air can cause the part-condensing of water vapor and recovery of the condensed water. The greater the amount of precooled circulation water, the more condensed water vapor, and the higher the efficiency of water-saving.

Exhaust steam from the steam turbine in the thermal power plant could be used as driving steam (position 13) of the lithium bromide absorption heat pump. The exhaust steam contains a large amount of low-temperature waste heat and a great deal of energy. However, it is usually difficult for it to be directly used in the actual production process due to the low energy quality, which results in a great deal of residual heat wasted [24]. In this system scenario, the residual heat of circulating cooling water and the waste heat of exhaust steam of the steam turbine were utilized effectively, and the evaporation water loss and the steam-water loss in the steam turbine were saved greatly. 


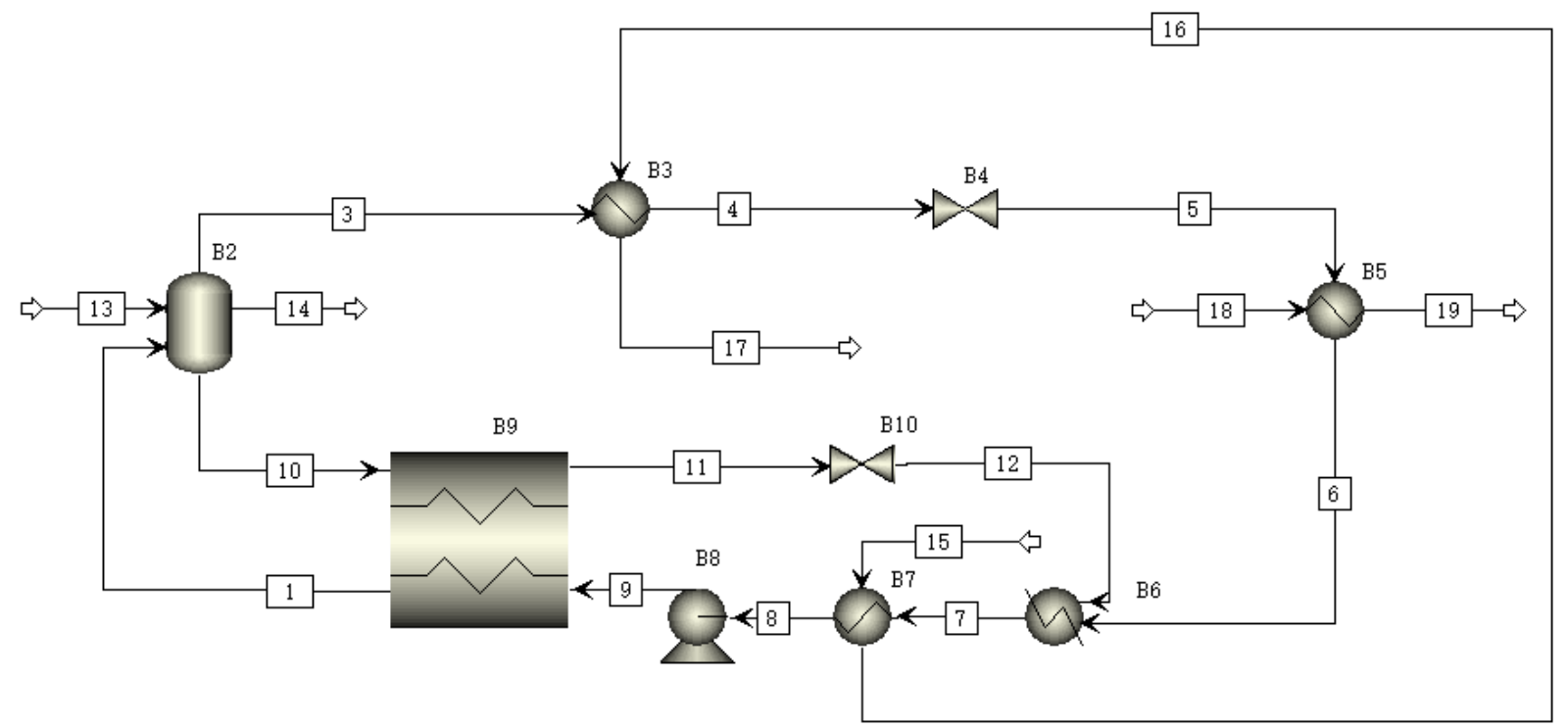

Figure 1. The cycle model implemented in Aspen Plus.

Table 1. Description of the main symbols used in the models.

\begin{tabular}{cccc}
\hline Module Symbol & Components & Module Symbol & Components \\
\hline B2 & Generator & B5 & Evaporator \\
B3 & Condenser & B8 & Pump \\
B7 & Absorber & B9 & Heat exchanger \\
\hline
\end{tabular}

\subsection{Method Description}

As shown in Figure 1, the design scenarios were simulated using Aspen Plus V10.0, which has an integrated structure and includes process-related unit operation modules besides components, properties, and state equations. The effects of several operating parameters, such as physical properties of the working medium, were explored in different working conditions. All the components of the system correspond to the equivalent modules. The descriptions of the module symbols used in the models are shown in Table 1, and typical state points of basic working condition results from Aspen Plus models are shown in Table 2. The operating parameters affecting the energy efficiency of the system were calculated and adjusted to achieve the best energy efficiency and stable operating to optimize the actual engineering process.

The 313-333 K water from external users first entered the absorber to absorb thermal energy and raise temperature, and then entered the condenser to further absorb thermal energy and satisfy temperature demand of external users, usually less than $363 \mathrm{~K}$. Driving steam entered the generator to offer thermal and then condensed. At the same time, the $316 \mathrm{~K}$ circulating cooling water from internal users in the thermal plant entered the evaporator to release thermal energy, and temperature of the circulating water was decreased to $305 \mathrm{~K}$, which was return to the main pipe of internal users. Some necessary assumptions regarding the mathematical model of system were adopted to simplify the model. The process was adiabatic and at steady state, condenser and generator pressures were the same, condenser and evaporator output streams were saturated, and pumping consumption was neglected.

The following is the basic cycle of lithium bromide solution: Dilute lithium bromide solution (position 1) flows into the generator (B2), which includes a heat module and flash module. The heat module is used to heat the lithium bromide solution, and the flash module separates gas from the liquid solution; then, the generated steam (3) flows into the condenser (B3) and reheats the returned water from external users. The concentrated solution of lithium bromide (position 10) passes through a heat exchanger (B9) and then 
flows into the absorber (B7). The water vapor condenses to water after passing through the condenser (B3) and flows into the evaporator (B5) to absorb heat, then returns to the absorber (B7) to mix with the concentrated lithium bromide solution (B6). Then, the lithium bromide solution flows through a pump (B8) into the heat exchanger (B9) to exchange heat with the concentrated lithium bromide solution from the generator (B2) after heating the water returned from external users. After being heated, the lithium bromide solution flows into the generator (B2) to complete the lithium bromide solution cycle.

Table 2. Typical stream result in the Aspen Plus model.

\begin{tabular}{ccccc}
\hline State Point & Position & Temperature (K) & Pressure (KPa) & Flow Rate (t/h) \\
\hline & 15 & 328 & 300 & 5500 \\
Absorber & 16 & 341 & 300 & 5500 \\
B7 & 7 & 353 & 4.16 & 1650 \\
& 8 & 349 & 4.16 & 1650 \\
Condenser & 17 & 353 & 300 & 5500 \\
B3 & 3 & 427 & 53 & 112 \\
& 4 & 356 & 53 & 112 \\
Generator & 13 & 523 & 600 & 113 \\
B2 & 14 & 432 & 600 & 113 \\
& 3 & 427 & 53 & 112 \\
Evaporator & 10 & 427 & 53 & 1538 \\
B5 & 18 & 316 & 200 & 5400 \\
& 19 & 305 & 200 & 5400 \\
Heat Exchanger & 5 & 303 & 4.16 & 112 \\
B9 & 6 & 303 & 4.16 & 112 \\
& 9 & 353 & 53 & 1538 \\
\hline
\end{tabular}

\section{Results}

The effects of physical properties of working media in different operating conditions were adjusted and optimized to achieve the best energy efficiency and economy. Specific simulation results and discussions are described hereafter.

\subsection{Effect of Evaporation Parameters}

The water return temperature of network water supply has little or no effect on the COP of the recovery system of circulating cooling wastewater heat and water resources using a lithium bromide absorption heat pump, and the increase in water supply temperature and driving steam consumption decreased the COP [25]. A higher water supply temperature of $363 \mathrm{~K}$ or more can promote the energy efficiency of the whole system and make it even more efficient in practical applications, especially in the co-generation industry. Considering the economic and stable operation of the whole system, this study combined practical engineering parameters and discussed the influence of different evaporation pressures on the $\mathrm{COP}$ of the system. The temperature of supply and return water varied from $328 \mathrm{~K}$ to $353 \mathrm{~K}$, when the system performance was more economical and stable. For some specific applications, or even to obtain saturated steam, the hot water could be heated further to a higher temperature by a peak heater [26], or directly using the second type of absorption heat pump.

The COP in the present work represents the sum of heating COP and cooling COP. Evaporation temperature is consistent with evaporation pressure (position 5 and 6 in Figure 1); the higher the evaporation pressure, the higher the evaporation temperature, thus only the evaporation pressure was studied in this work. The calculation was conducted in the case: driving steam was kept at $523 \mathrm{~K}, 0.6 \mathrm{MPa}$ and $145 \mathrm{t} / \mathrm{h}$, the water return and supply temperatures of network water users were $328 \mathrm{~K}$ and $353 \mathrm{~K}$, respectively, and the return temperature of the circulating cooling water was kept at $316 \mathrm{~K}$. The results are shown in Figure 2. 


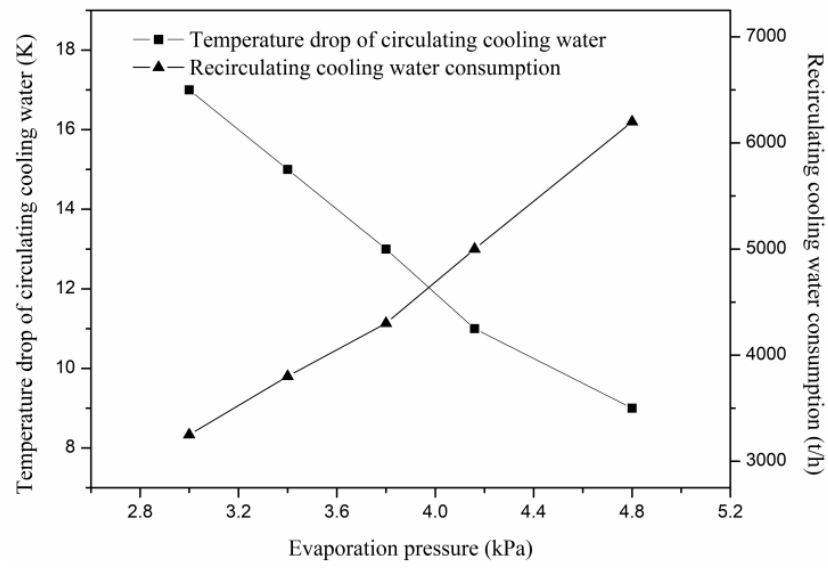

(a)

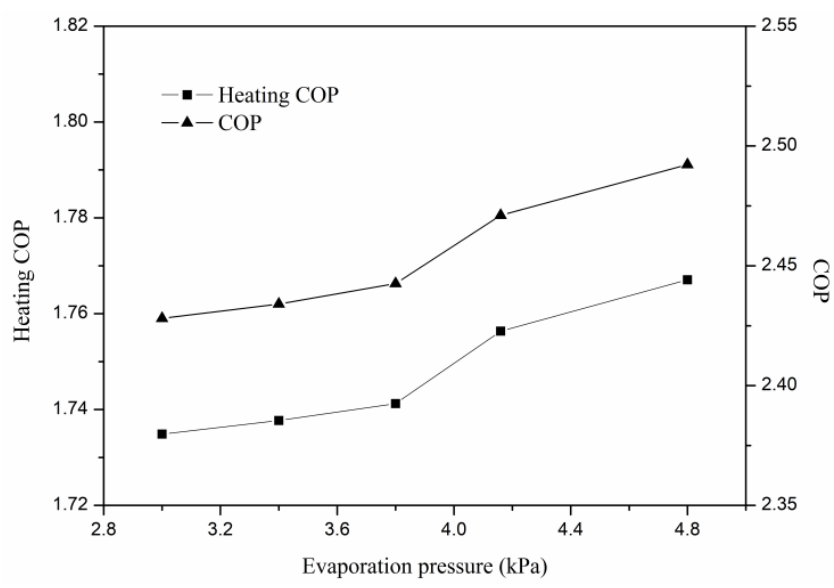

(b)

Figure 2. Effect of evaporator pressure on different parameters: (a) temperature drop and consumption of circulating cooling water; (b) heating COP and total COP.

In Figure 2a, the left ordinate represents the temperature drop of circulating cooling water, i.e., the temperature difference between the water entering and leaving the cooling tower, and the horizontal axis represents the evaporating pressure in the evaporator. As can be seen from Figure 2a, the increase in evaporation pressure caused the temperature of the circulating cooling water to decrease. Due to the return temperature of circulating cooling water being kept at $316 \mathrm{~K}$, the supply temperature of circulating cooling water was higher than before, which is disadvantageous to the users of cooling water. The right ordinate represents the consumption of recirculating cooling water; circulating cooling water consumption increased with the increase in evaporation pressure. The parameters of driving steam and the water supply and return temperature of network water users were constant; therefore, the refrigerating capacity and heating capacity were basically unchanged, meaning that there is a counter-trend between the temperature drop and consumption of circulating cooling water, which is in accordance with the law of energy balance.

In Figure $2 b$, the left ordinate represents the heating COP of the recovery system, the right ordinate represents the sum of heating COP and cooling COP, and the horizontal axis represents the evaporating pressure in the evaporator. Heating COP is the ratio of the heat capacity produced by the system to the heat absorbed from an external heating source: driving steam in this case. In the same way, cooling COP is the ratio of the refrigerating capacity produced by the system to the heat absorbed from an external heating source. The variation trend is shown in Figure $2 \mathrm{~b}$. The heating COP of the heat pump and the sum of system COP both increased gradually with the increase in evaporation pressure. The modelling result indicated that the evaporation pressure and temperature have a great influence on the heating COP and the system COP and can raise the thermal economy of the system. This trend is consistent with the conclusion of Yang [27], who verified that the parameters of evaporation in an evaporator are proportional to the system COP. The improvement of the energy-saving performance of the model depends on the development of the heat pump technology. In theory, the system performance can be optimized and improved by adjusting and matching some parameters such as cycle design, working medium selection, system component heat and mass transfer enhancement, the system control strategy [23], etc., which can provide operation guidance for engineering practice under the consideration of actual operating conditions.

\subsection{Effect of Temperature Difference between Evaporation and Condensation}

The evaporation temperature and condensation temperature are both crucial parameters in absorption heat pump systems. The evaporation temperature is consistent with evaporation pressure, which has been discussed in Section 3.1. Additionally, temperature difference between evaporation and condensation is studied here. Group 1 and group 2 are 
two groups of different working conditions: in group 1, the driving steam is kept at $523 \mathrm{~K}$, $0.6 \mathrm{MPa}$ and $145 \mathrm{t} / \mathrm{h}$, water return and supply temperature of network water users are kept at $328 \mathrm{~K}$ and $353 \mathrm{~K}$, respectively, and the refrigerating capacity produced by the system is constant; in group 2, the parameters of driving steam and water supply temperature of network water users are variable, and changes in specific parameters are described in the analysis below.

In Figure 3, the left ordinate represents the COP of the recovery system in group 1; the right ordinate represents the system COP of group 2. The system COP represents the sum of heating COP and cooling COP. The horizontal axis represents the temperature difference between evaporation and condensation, which means the evaporation temperature in the evaporator and condensation temperature in the condenser. As shown in Figure 3, results show that the COP of the heat pump system decreased with the increase in temperature difference between evaporation and condensation both in group 1 and group 2.

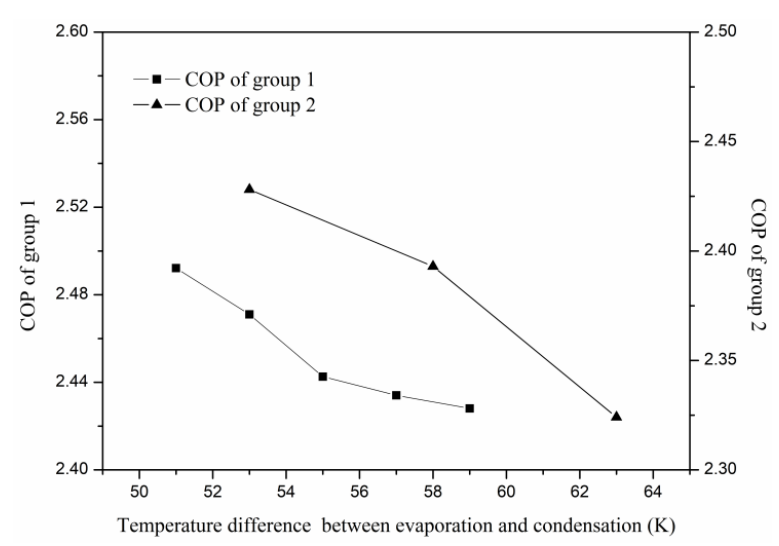

Figure 3. Effect of temperature difference between evaporation and condensation on COP.

In group 1, the parameters of driving steam and water return and supply temperature of network water users were constant, and refrigerating capacity produced by the system was constant, which meant that the heat released by circulating cooling water was unchanged. Under these conditions, the COP of heat pump system decreased with the increase in temperature difference between evaporation and condensation, which is consistent with the conclusion of Sun [28], who demonstrated the effect of temperature difference between evaporation and condensation on system COP. In the same way, in group 2, with the increase in temperature difference between evaporation and condensation, the consumption of driving steam, the water supply temperature of network water users, and the consumption of circulating cooling water increased; in the meantime, the heat capacity and refrigerating capacity produced by the system increased, and the heat absorbed from external heating source also increased. Taken together, the system COP decreased with the increase in temperature difference between evaporation and condensation. The probable reason is that when temperature difference between evaporation and condensation increases, the refrigerating capacity decreases linearly with the increase in the power consumption of the system, and the evaporation temperature decreases faster than the condensation temperature; thus, the performance coefficient of the system decreases due to increased effects of evaporation temperature. When temperature difference between evaporation and condensation increases from $51 \mathrm{~K}$ to $59 \mathrm{~K}$, the system performance coefficient decreases by $2.64 \%$, and the refrigeration capacity decreases by $1 \%$.

\subsection{Effect of Generating Temperature}

The effect of the consumption of circulating cooling water and water supply temperature of network water users on the COP of the system have been reported in many studies $[25,26]$. However, the contribution of generating temperature on system COP is 
not yet clear. Temperature and pressure of the driving steam are related to the generating temperature of the generator; therefore, the effect of generating temperature (positions 2 and 3 in Figure 1) on the driving steam parameters, heating capacity, and the COP of the system are explored and analyzed in this section. The changes of heat from driving steam source, heating capacity, and COP of the system were simulated while keeping the temperature of driving steam and return water constant, as well as the inlet and outlet temperatures of the circulating cooling water.

In Figure $4 \mathrm{a}$, the left ordinate represents the consumption of driving steam, the right ordinate represents the system COP (the sum of heating COP and cooling COP), and the horizontal axis represents the generating temperature in the generator. The driving steam consumption increased and the COP of the system decreased with the increase in generating temperature. The reason is that the change in generating temperature will affect the condenser pressure and condenser temperature, which leads to the decrease in driving steam consumption. The consumption of driving steam indicates the heat absorption from the external heating source, which corresponds to heating capacity and cooling capacity and is inversely proportional to the system COP. This result was consistent with the conclusions of Zhang [29] and Che [26], who proved that the COP of heat pump recovery systems decreased with the increase in temperature difference between water supply and the return of network users or temperature difference between inlet and outlet circulating cooling water.



(a)

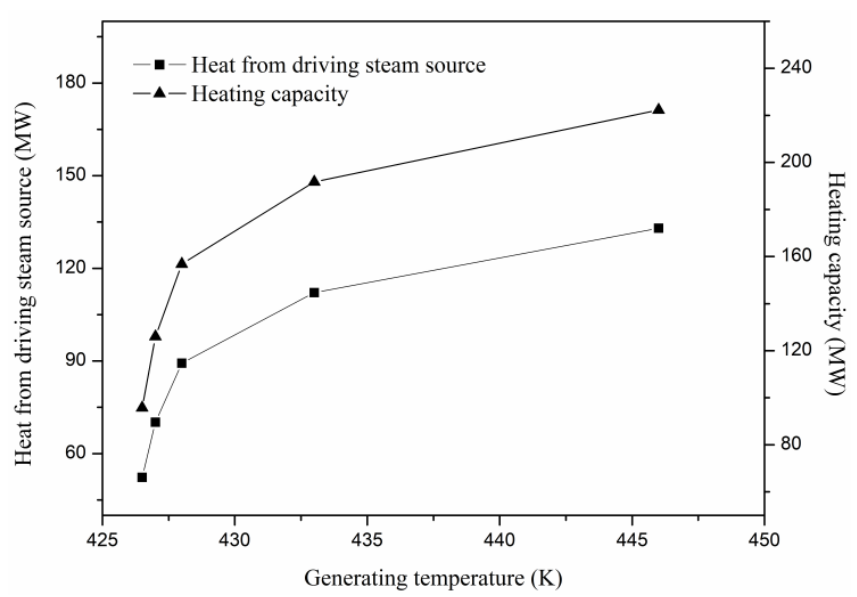

(b)

Figure 4. Effect of generating temperature on different parameters: (a) driving steam consumption and COP; (b) heat from driving steam source and heating capacity.

In Figure $4 b$, the left ordinate represents the heat from the driving steam source, and the right ordinate represents the heating capacity produced by the recovery system, which was used to heat the network water. The horizontal axis represents the generating temperature in the generator. As shown in Figure $4 \mathrm{~b}$, the conclusion can be proved further; the heat from the driving steam source and heating capacity produced by the heat pump system both increased with the increase in generating temperature. The heat from driving steam source comes from the driving steam consumption when temperature of driving steam is constant; therefore, the more driving steam consumed, the more heat absorbed from the driving steam source and heating capacity produced by the heat pump system. However, the system COP was decreased with the increase in heat from the driving steam source and heating capacity because the system COP is a composite parameter: it is a sum of cooling COP and heating COP, which is a result of heating production capacity divided by the total heat absorption from the driving steam source.

All these results show that it is feasible to improve the system coefficient of performance by optimizing some parameters of waste heat recovery systems using heat pumps 
in many fields such as the food, paper, electroplating, metal processing and chemical industries, etc., and the suitability depends on the existing environmental and economic framework conditions of the local electricity grid and the COP [30].

\section{Discussion}

Based on the simulation results, the actual operation case, and parameters of the power plant, the following results are regarded as guidance for optimizing operation parameters after retrofit: in the present case, when evaporation parameters were $4.2 \mathrm{kPa}$ and $303 \mathrm{~K}$, temperature difference between evaporation and condensation was $53 \mathrm{~K}$, driving steam parameters were $523 \mathrm{~K}$ and $82 \mathrm{t} / \mathrm{h}$, water supply temperature was $343 \mathrm{~K}$, thus the system COP had the best value of 2.611. On the basis of the safe and stable operation of the system, the evaporation pressure can be increased properly, temperature difference between evaporation and condensation can be minimized, and the generating temperature can be decreased to improve the COP of the whole system. However, the combination of the best values of the parameters does not mean the best values for the whole system; it needs to be adjusted in a reasonable range according to the actual operation.

On the basis of optimized operation, several technical scenarios of waste heat recovery from circulating cooling water were introduced to compare and analyze, with the assumptions as follows: the treatment capacity of circulating cooling water in one single cooling tower is $5000 \mathrm{t} / \mathrm{h}$, the temperature of circulating cooling water reduces from $316 \mathrm{~K}$ to $305 \mathrm{~K}$, and the total water loss of evaporation, floating, and sewage in the cooling tower is $1.71 \%$. The circulating cooling water will evaporate in $59 \mathrm{~h}$ without water-saving measures or replenishment, therefore four technical scenarios are listed in Table 3: Scenario 1 represents a cooling tower with a hot air mixture, which is popular in some existing thermal plants; Scenario 2 represents $10 \%$ of circulating water entering the heat pump; Scenario 2 represents $20 \%$ of circulating water entering the heat pump; and Scenario 4 represents all the circulating water entering the heat pump. Scenario 1 represents condensing and recovering water from the wet saturated air coming out of cooling tower a using hot air mixing device; the other three scenarios precool part or all of the circulating water by heat pump; therefore, the temperature and moisture content of the wet saturated air in the cooling tower can be reduced, so that some water vapor can be condensed and recovered. The more precooling circulating water, the more water vapor can be condensed, the more obvious water saving effect.

Table 3. Water saving performance comparison of several technical scenarios.

\begin{tabular}{cccccc}
\hline Items & Unit & Scenario 1 & Scenario 2 & Scenario 3 & Scenario 4 \\
\hline Device & $/$ & hot air mixture & $\begin{array}{c}\text { heat pump with } \\
10 \% \text { cooling water }\end{array}$ & $\begin{array}{c}\text { heat pump with } \\
\text { 20\% cooling water }\end{array}$ & $\begin{array}{c}\text { heat pump with } \\
100 \% \text { cooling water }\end{array}$ \\
\hline Water Saving & $\mathrm{t} / \mathrm{h}$ & 9.8 & 23 & 36 & 85.5 \\
Water Saving Rate & $\%$ & 13.87 & 27 & 42 & 100 (theoretical) \\
Annual Water Saving & $\mathrm{t}$ & 70,560 & 165,600 & 259,200 & 615,600 \\
\hline
\end{tabular}

According to Table 3, it is clear that waste heat recovery by heat pump has a better water saving performance. The water saving rate can theoretically reach $100 \%$ when all the circulating water enters the heat pump, which means that one cooling tower with a treatment capacity of $5000 \mathrm{t} / \mathrm{h}$ could be completely replaced by a heat pump system. This is a sign that the waste heat recovery scenario can greatly reduce the evaporation loss of circulating cooling water and save water resources.

The economy of the technical scenario is vital and must be considered in actual production, besides the COP of the waste heat recovery system. In the present work, the static payback period method [31] was used to analyze and compare the above waste heat recovery scenarios of circulating cooling water. The static payback period is calculated as follows: the total original investment of the project is divided by the annual net cash flow 
of the project, which is the differential value between the annual operating income and annual operating cost of the project [32]. The total original investment is the purchase cost of the main equipment, which mainly includes the cooling tower, heat pump, water saving measures, civil construction and installation, etc., as listed in Table 4. For the sake of brevity, Scenario 2, which is similar to Scenario 3, is omitted.

Table 4. Comparison of investment costs (unit: million USD).

\begin{tabular}{cccc}
\hline Items & Scenario 1 & Scenario 3 & Scenario 4 \\
\hline Cost of Cooling Tower & $\begin{array}{c}\text { 65.14 (including fans } \\
\text { and pumps) }\end{array}$ & $\begin{array}{c}\text { 65.14 (including fans } \\
\text { and pumps) }\end{array}$ & 0 \\
Cost of Water Saving Measures & 42.48 & 21.24 & 0 \\
Cost of Heat Pump & 0 & $113.28(1 \mathrm{MW} \times 30 \mathrm{MW})$ & $155.76(3 \mathrm{MW} \times 50 \mathrm{MW})$ \\
Cost of Civil Construction and Installation & 51.68 & 95.86 & 224.29 \\
Total Investment Costs & 180.82 & 335.45 & 785.03 \\
\hline
\end{tabular}

Annual operating income refers to the annual income from hot water supply to external users generated by recovering the waste heat of circulating cooling water, which reduces the steam demand for the production of hot water and reduces the production cost of enterprises. The annual operating cost mainly refers to the power cost and the maintenance and management costs of the system, such as electricity consumption and water replenishment cost. In addition, the cost of driving steam consumption of the heat pump operation is considered in the operating cost. The comparison of operating costs and income are listed in Table 5.

Table 5. Comparison of annual operating costs and annual income (unit: million USD).

\begin{tabular}{cccc}
\hline Items & Scenario 1 & Scenario 3 & Scenario 4 \\
\hline Electricity Consumption Cost & 11.89 & 0.92 & 4.59 \\
Water Replenishment Cost & 7.50 & 5.10 & 0 \\
Cost of Driving Steam & 0 & 165.25 & 856.40 \\
Total Annual Operating Costs & 19.40 & 171.34 & 860.93 \\
Annual Income & 0 & 324.83 & 1624.15 \\
\hline
\end{tabular}

All the calculation results in the present work were based on the following principles: the annual operating time was $7200 \mathrm{~h}$, the water price was $0.1416 \mathrm{USD} / \mathrm{t}$, the electricity price was $70.7 \mathrm{USD} / \mathrm{MWh}$, and the heat price was $4.25 \mathrm{USD} / \mathrm{GJ}$.

According to the economic comparison results in Tables 4 and 5, the total investment cost and annual operating cost of Scenario 4 with a heat pump is much higher than Scenario 1 with a cooling tower, and Scenario 3 with a heat pump and cooling tower is in the middle, although the construction cost of cooling towers with corresponding circulating water treatment capacity in Scenario 4 is saved. However, the annual income of Scenario 4 is the best of all the scenarios, because the evaporation water loss of Scenario 4 is nearly zero. Scenario 1 is a one-time investment project without any recovery cost and all the circulating cooling water heat is wasted; Scenario 4 can not only decrease the construction cost of the cooling tower and operation costs of eliminating white smoke, but also decreases the humidity content of the wet saturated air even further using a small amount of the high-temperature heat source produced by the heat pump to heat the humid saturated air, which achieving the goal of water recovery and energy conservation. This design scenario will have very broad application prospects in the circulating cooling water treatment of electric power, chemical manufacturing, and other industries.

As shown in Tables 4 and 5, the economic analysis and comparison results show that the total investment cost of Scenario 4 with a heat pump is USD 785.03 million, and the annual operating costs and annual income are USD 860.93 million and USD 1624.15 million, respectively. The static payback period is calculated as approximately two years, assuming that all of the recovered waste heat can be fully used with $100 \%$ efficiency. However, it is 
impossible to make full use of heat energy in actual industry due to the technical constraints and practical application conditions. Assuming that $40 \%$ of the recovered waste heat was used in the recovery system, the static payback period of Scenario 3 with a cooling tower and heat pump is about four years, and the payback period of Scenario 4 with a heat pump is approximately three years. The static payback period of scenarios with heat pumps is not very long and far less than the lifetime of the equipment, which indicates that it is feasible to recover the waste heat of circulating cooling water and save water resources with a heat pump.

\section{Conclusions}

The energy-saving performance of a cooling water waste heat recovery system and water resource recovery system of with a lithium bromide absorption heat pump was simulated and analyzed using Aspen plus V10.0 software, and the results indicated that the evaporating pressure and temperature have great influence on the system performance, which can improve the thermal economy of the system. The heat from driving steam and heating capacity both increased with the increase in generating temperature, while the increase in temperature difference between evaporation and condensation constrained the operation of the heat pump system. In the present case, when the evaporation parameters were $4.2 \mathrm{kPa}$ and $303 \mathrm{~K}$, temperature difference between evaporation and condensation was $53 \mathrm{~K}$, driving steam parameters were $523 \mathrm{~K}$ and $82 \mathrm{t} / \mathrm{h}$, and water supply temperature was $343 \mathrm{~K}$, the system COP had the best value of 2.611. The economic analysis and comparison showed that the scenario of $100 \%$ heat recovery by the heat pump had the best comprehensive economic performance, although it had the highest total investment cost and annual operating cost. The annual saving amount of water was about $615,600 \mathrm{t}$ for a cooling tower with a treatment capacity of $5000 \mathrm{t} / \mathrm{h}$. The results of static investment indicated that the payback period of recovery scenario from a circulating cooling wastewater heat system with a heat pump is about three years, which is less than other scenarios and far less than the lifetime of the equipment. It indicates that the recovery scenario of a heat pump is feasible. The heat economy of the system can be improved by using the heat pump waste heat recovery scenario, which has important guiding significance to engineering practice. According to the simulation results and the safe and stable operation of the system, considering the actual operation conditions and parameters of the power plant, it is suggested that the evaporation pressure should be increased properly, the temperature difference between evaporation and condensation should be reduced, the generating temperature should be lowered, and the COP of the system should be increased. However, the best value combination of the parameters does not mean the best value of the whole system; it also should be adjusted in a reasonable range according to the actual operation of the whole system. The next step is to carry out a series of pilot tests, further simulating and optimizing the whole system using lithium bromide absorption heat pumps in a real petrochemical plant based on the actual parameters of field operation.

Author Contributions: Data curation, Y.R.; Funding acquisition, Z.H.; Methodology, Y.R.; Project administration, Z.H.; Supervision, Z.W. and Y.L.; Writing-original draft preparation, L.Y.; Writingreview and editing, L.Y. and Z.H. All authors have read and agreed to the published version of the manuscript.

Funding: This research was funded by the Program of Introducing Talents of Discipline to Universities [B08026] and Key Laboratory for Technology in Rural Water Management of Zhejiang Province, and Scientific research foundation of Zhejiang University of Water Resources and Electric Power.

Institutional Review Board Statement: Not applicable.

Informed Consent Statement: Not applicable.

Data Availability Statement: Data sharing not applicable. 
Acknowledgments: The authors would like to thank the editor and the reviewers who provided many valuable comments to improve the paper. Li Yang would also like to thank the help of Jinshi Wang and the supervisor Zhihua Wang.

Conflicts of Interest: The authors declare no conflict of interest.

\section{References}

1. Sheikholeslami, M.; Farshad, S.A.; Ebrahimpour, Z.; Said, Z. Recent progress on flat plate solar collectors and photovoltaic systems in the presence of nanofluid: A review. J. Clean. Prod. 2021, 293, 126119. [CrossRef]

2. Forman, C.; Muritala, I.K.; Pardemann, R.; Meyer, B. Estimating the global waste heat potential. Renew. Sustain. Energy Rev. 2016, 57, 1568-1579. [CrossRef]

3. Xia, L.; Liu, R.; Zeng, Y.; Zhou, P.; Liu, J.; Cao, X.; Xiang, S. A review of low-temperature heat recovery technologies for industry processes. Chin. J. Chem. Eng. 2019, 27, 2227-2237. [CrossRef]

4. Sheikholeslami, M.; Jafaryar, M. Nanoparticles for improving the efficiency of heat recovery unit involving entropy generation analysis. J. Taiwan Inst. Chem. Eng. 2020, 115, 1-12. [CrossRef]

5. Wang, X.; Zhuo, J.; Liu, J.; Li, S. Synergetic process of condensing heat exchanger and absorption heat pump for waste heat and water recovery from flue gas. Appl. Energy 2020, 261, 114401. [CrossRef]

6. Sheikholeslami, M.; Farshad, S.A.; Said, Z. Analyzing entropy and thermal behavior of nanomaterial through solar collector involving new tapes. Int. Commun. Heat Mass Transf. 2021, 123, 105190. [CrossRef]

7. Sheikholeslami, M.; Farshad, S.A. Investigation of solar collector system with turbulator considering hybrid nanoparticles. Renew. Energy 2021, 171, 1128-1158. [CrossRef]

8. Zhou, H.; Wang, W.; Hen, G.; Zhang, Q. Water Conservation and Plume Abatement Technology of Mechanical Draft Cooling Towers. Energy Energy Conserv. 2021, 2, 160-163.

9. Notaro, V.; Puleo, V.; Fontanazza, C.M.; Sambito, M.; Loggi, G.L. A decision support tool for water and energy saving in the integrated water system. Procedia Eng. 2015, 119, 1109-1118. [CrossRef]

10. Freni, G.; Sambito, M. Energy saving and recovery measures in integrated urban water systems. AIP Conf. Proc. 2017, 1906, 190008

11. Zhu, X.; Niu, D.; Wang, X.; Wang, F.; Jia, M. Comprehensive energy saving evaluation of circulating cooling water system based on combination weighting method. Appl. Therm. Eng. 2019, 157, 113735. [CrossRef]

12. Ma, L.B.; Ren, J.X.; Li, F.Q.; Zhang, L.J.; Li, M.Q. The discussion on cooling optimization of natural draft wet cooling tower. IOP Conf. Ser. Earth Environ. Sci. 2018, 199, 032074. [CrossRef]

13. Cai, B.; Zhu, W. Simulation of Frequency Conversion and Energy Saving of Circulating Water System. IOP Conf. Ser. Mater. Sci. Eng. 2018, 452, 032135. [CrossRef]

14. Terzi, E.; Cataldo, A.; Lorusso, P.; Scattolini, R. Modelling and predictive control of a recirculating cooling water system for an industrial plant. J. Process Control 2018, 68, 205-217. [CrossRef]

15. Li, T.; Yang, M.; Feng, X. A Simulation-Optimisation Method for Targeting the Optimal Placement of Heat Pumps in Heat Exchanger Networks. Chem. Eng. Trans. 2019, 76, 319-324.

16. Li, J. The Application of Absorption Heat Pump in Energy Saving and Renovation Project of Heat and Power Generation; Zhongyuan University of Technology: Zhengzhou, China, 2018.

17. Gou, X.; Fu, Y.; Shah, I.A. Research on a Household Dual Heat Source Heat Pump Water Heater with Preheater Based on ASPEN PLUS. Energies 2016, 9, 1026. [CrossRef]

18. Wang, M.; Deng, C.; Wang, Y.; Feng, X. Exergoeconomic performance comparison, selection and integration of industrial heat pumps for low grade waste heat recovery. Energy Convers. Manag. 2020, 207, 112532. [CrossRef]

19. Zhang, Q.; Zhang, X.; Yin, C.; Liu, F.; Wang, G. Experimental evaluation of heat transfer performance of falling film evaporator for wastewater source heat pump with backwash system. Int. J. Refrig. 2020, 113, 80-93. [CrossRef]

20. Estefanía, H.B.; Emilio, N.P.; José, M.C. Optimal design and operation of a central domestic hot water heat pump system for a group of dwellings employing low temperature waste heat as a source. Energy 2019, 188, 115979.

21. Liu, C.; Wang, Z.; Han, W.; Kang, Q.; Liu, M. Working domains of a hybrid absorption-compression heat pump for industrial applications. Energy Convers. Manag. 2019, 195, 226-235. [CrossRef]

22. Mansouri, R.; Boukholda, I.; Bourouis, M.; Bellagi, A. Modelling and testing the performance of a commercial ammonia/water absorption chiller using Aspen-Plus platform. Energy 2015, 93, 2374-2383. [CrossRef]

23. Chen, G.; Shi, Y. State-of-the-art Absorption Refrigeration and Heat Pump Cycles. J. Refrig. 2017, 38, 1-22.

24. Zhao, H. Technical Economy Research of Using Absorption Heat Pump to Recovery the Waste Heat of Power Plant Circulating Water; North China Electric Power University: Beijing, China, 2012.

25. Yang, L.; Ren, Y.; Zhang, X.; Wang, Z.; Wang, J.; Wang, X.; Hang, Z. Modelling Investigation of Optimum Operating Conditions for Circulating Water Waste Heat Recovery. Chem. Eng. Trans. 2020, 81. [CrossRef]

26. Che, D.; Lv, J.; Gao, L.; Li, S.; Bai, Z. Using lithium bromide absorption heat pump to recycle circulating water heat: A simulation. Therm. Power Gener. 2014, 43, 38-43.

27. Yang, B. Study on New Types of Absorption Heat Transformer Based on Low Grade Waste Heat Recovery. Master's Thesis, Shenyang Jianzhu University, Shenyang, China, 2016. 
28. Sun, J.; Ma, S.; Huo, C.; Ge, Z.; Du, X.; Yang, Y. Performance analysis of a new hybrid unit combined with absorption and compression cycles. Acta Energ. Sol. Sin. 2020, 41, 375-380.

29. Zhang, X.; Chen, H. Thermodynamic Analysis of Heat Pump Heating Supply Systems with Circulating Water Heat Recovery. Proc. Csee 2013, 33, 1-8.

30. Schlossera, F.; Arpagaus, C.; Walmsley, T.G. Heat Pump Integration by Pinch Analysis for Industrial Applications: A Review. Chem. Eng. Trans. 2019, 76. [CrossRef]

31. Guo, X. Economic Evaluation Index and method of electric power technology. Low Carbon World 2014, 3, 76-78.

32. Sheng, F.; Zhou, Y.; Wang, S.; Jin, Y.; Liu, Z.; Li, H.; An, X. Optimization analysis of compound heat pump system design for waste heat recovery of printing and dyeing waste gas. Energy Conserv. 2020, 39, 91-95. 